\title{
Escola e Cultura: (des) memórias
}

\author{
Antonio Carlos Rodrigues de Amorim
}

Professor Associado da Faculdade de Educação da Unicamp. acamorim@ unicamp.br

Parte do Memorial de Concurso de Livre Docência na disciplina Escola e Cultura, defendido em 2011.

Ilustrações por:

Fernanda Cristina Martins Pestana

Esta escrita , um combate à memória que, em última instância, haverá de revelar ou originar a verdade do tempo.

Por isso, aposta na qualidade sensorial que é apreendida como signos e que vence o imperativo que nos força a buscar os significados.

Escola e Cultura se forma como uma coexistência virtual de passado e presente. Escola e Cultura, em um memorial, não se forma posteriormente a uma recordação, às lembranças, mas, sobretudo, simultaneamente a elas.

$* * * * * * * * * * * * * * * * * * * * * * * * * * * * * * * * * * * * * * * * * * * * * * * *$

Esta escrita, aprendizagem: referente ao presente que tem

sido e relativo ao presente a respeito do qual se considera ou se julga como passado. $\mathrm{O}$ passado, então, coexiste com o

presente.

Transformar o memorial Escola e Cultura em acontecimento de Escola e Cultura é uma das maneiras que desejo, inspirado em Gilles Deleuze, por um devir no que podemos considerar como experiência do passado. 
Esta escrita, fragmento, tratamento dramático que em Escola e Cultura se efetua pela perturbação causada por um passado que emerge de uma maneira nova e deslumbrante e que não encontra um narrador, apenas sensações.

Objetos virtuais que somente podem existir como fragmentos - e mais, Escola e Cultura: fragmentos de si mesmos uma vez que se encontram como objetos perdidos e que só existem se forem recordados.

Escola e Cultura se trata da experiência da profunda diferença e da não-identidade que se alcança por meio das relações de semelhança e contigüidade.

Escola e Cultura, não estamos tratando do nascimento de uma disciplina, em que a narrativa seja capaz de transformá-la em um ente, um ser, plenos de vida. É a amplitude do movimento forçado, como se fosse a eminência da morte, uma perda que se ocorre e perfura o meio Escola e Cultura, e torna-se a condição de sua forma. 


\section{A escrita, feminina}

Pula a corda, com mais força e velocidade, entra na corda e salta e brinca e se agita. Aquece-se. No dia de frio, brincar de corda, ficar pulando e sem frio.

A escrita faz as ondas, as vibrações e as correntezas de ar da corda, e leva golpes e sai e entra e se movimenta. A escrita sem frio. Toma a forma da corda em movimento e se solta. Solta-se, e pula e brinca e se agita.

$\mathrm{Na}$ brincadeira, a escrita encontra o menino travesso, perdido no bosque, numa noite, com uma lua entre as árvores, e um rugido feroz de leão. A escrita, perdida do menino travesso, caminha até uma casa abandonada na qual há uma luz. No movimento aprendido na corda, corre, corre para a casinha abandonada.

Abandona-se a velocidade da corda, sua textura, sua ondulação e seu arredondamento, seu curso de brincadeira, e encontra-se no controle de um compasso que a faça deslizar em um outro ritmo, do qual nem se lembra mais, mas que com ele se corporificou. A missão da escola de ir ao encontro do menino travesso que se esquecesse da corda, e fizesse do frio a companhia sensível, um estilo. 

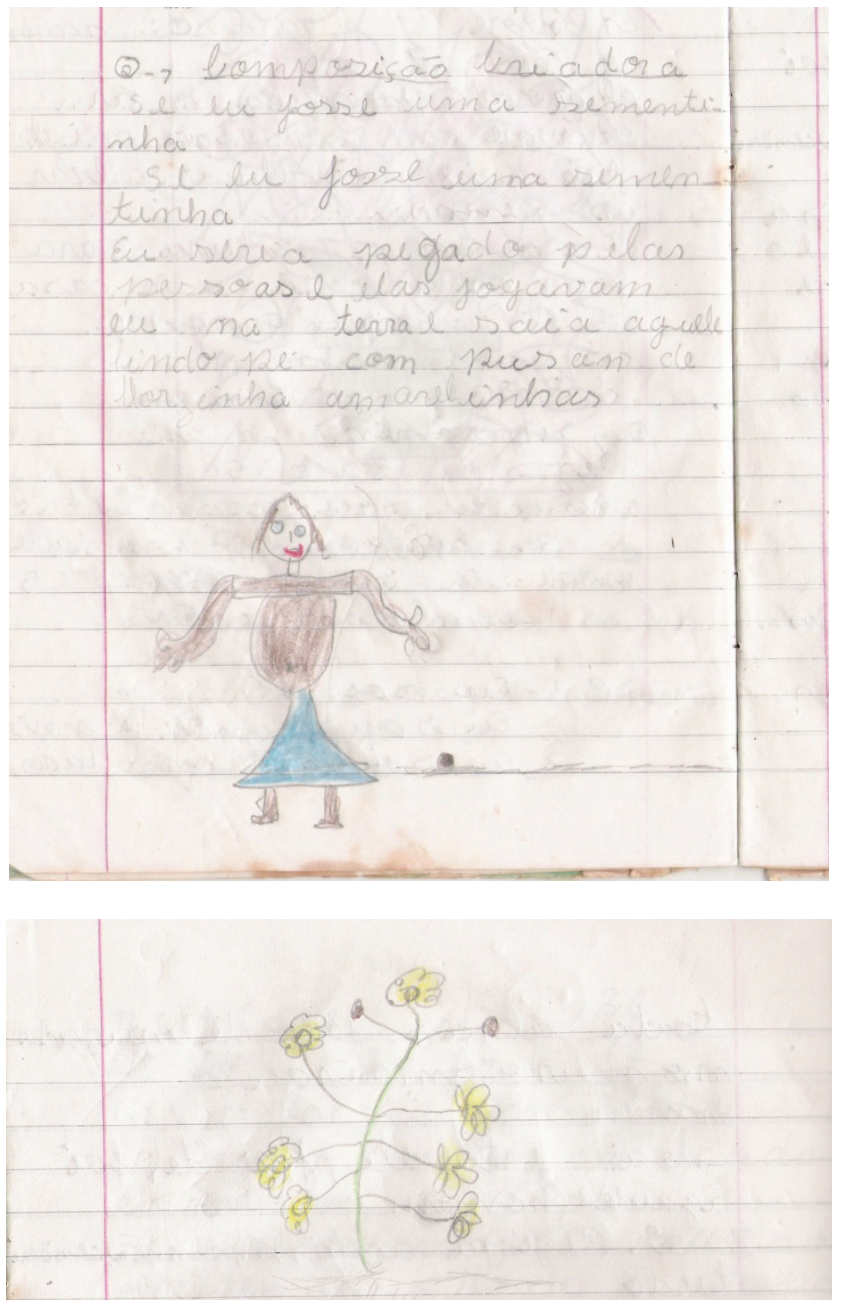

Caderno de Tarefas. 1ª Série do Primário. São Geraldo/MG, 22/09/1976.

Ser-semente-flores amarelinhas, de camomila. Gosto amargo da delicadeza, pautada em linhas de caderno. A escrita é semeada e vira uma 'pusam' de florzinhas. Quem semeia colhe do jardim de 
uma infância cujo chá de camomila aquece. A escrita, agora, borbulha no chá, é infusão floral, estende-se pelo abandono da casa, que hoje se ruiu, deslocou-se de qualquer memória visualmente marcada, a não ser por imagens, e está espalhada em sementes que se estendem no presente, compondo palavras, frases e sensações em devir. A escrita devém passado.

Atravessando as frestas de uma cerca de bambu, escoa a escrita disforme, em parreiras de uva, gosto do figo, mangas sempre verdes, goiabeira em fogo, experiências 'científicas' no jardim, a criação de um ambiente para a vida de uma joaninha, que foge, bate as asas e voa, deixando a morada a ela destinada. A escrita não se destina, tampouco quer se fazer representar.

Fuja, escrita, bata as asas e dentro da sua forma resista aos tombos, aos risos, aos deslocamentos e aos insistentes lápis, canetas e diagramas que desejam sua diferença.

Tempo da escrita: desmemoriada, enlouquece; inadequada, embrutece; visceralmente arrebatada, transforma-se em música e com ela se enternece. Sobrevive imaginando-se letra e som.

Existência subtraída da forma, a escrita ampara-se em nome de. Ao contrário do que se esperaria ao ouvir seu nome pela primeira vez e iniciar seu caminho de fixidez e morte na identidade, a escrita esquece toda e cada vez, e repetidamente, a nomeação e colore-se em algo que não faz parte do caderno, num registro virtual. 
Professor

De um sorteio, o pequeno mimeógrafo.

De um canto da parede, o quadro a giz.

De um grupo de bonecos de pano e bichos de pelúcia, as provas a serem corrigidas.

De umas memórias, a alfabetização de desconhecidos.

De cada escola à beira da estrada, a afinidade.

De diários e tarefas, a substituição.

De encontros em encontros, a pulsão da aula.

De passagem, o ritual do afeto.

De sensibilidades, a violência da educação que marca.

De contágio, a transmutação.

De linhas variantes, a janela e os descascados da tinta que envelhece.

De desenhos ondulantes na paisagem, o verde das montanhas e o precipício da partida.

Da cantina, o mingau.

Da invenção, a resistência.

Da fuga, a impossibilidade.

De viver, o possível efêmero.

Espera confeccionando pensamentos por fios que se emaranham, e que quando puxados, enroscam-se enovelados em superfícies cuja plasticidade opaca e disforme são as variações em multiplicidade que todo ser quase é e está.

Olhos de animais taxidermizados, compotas de peças anatômicas em formol e folhas, flores e ramos prensados. Cheiram à naftalina, e expulsam as traças, aquelas que perfuram pêlos, celulose e tinta.

Do grito, a respiração.

Do suspiro, o retorno.

Da fala, o abandono da voz.

Do sorriso, a vaga lembrança da primeira vez na escola.

Do choro e da persistência de se esvaziar do lugar, o sempre traço escola. 


\section{Ser - Professor}

Decidi fazer uma entrada na escrita, na intenção de compartilhar afinidades e dispersar sentidos, exatamente pela hifenação entre 'Ser-Professor'. Ou seja, o hífen como emergência estrutural da expressão das experiências, sua evidenciação e possibilidade de 'dar a ver' e que, segundo alguns dos referenciais que vão ao seu encontro, e são muitas vezes rapidamente, velozmente, abandonados, tal hífen necessita ser desconstruído, arruinado, movimentado violentamente em ambos os lados, perfurando o Ser e o Professor, fazendo deles, com eles, o Professer, Profeserssor, Serprofe, Rossefropres...

Um ovo que derrama a estabilidade de uma existência, e Faz de Clarice um ser cuja escritura nomadiza-se em gema, em clara,

Em oco.

Para além da definição e delimitação do que poderia 'Ser' ', 'Professor', buscam-se os efeitos, a expressão:

- em outras palavras

- em movimento

- em diferença

Se nas 'culturas', o hífen concentra sua pedagogia do Ser, as perguntas a respeito do que o hífen conta de nós mesmos/as, a quem interessam as narrativas de hífen, ou o quanto, em intensidade, o hífen trabalha com sistemas de significação e jogos de representação, de identificação num estilo que imprima ao 'Ser' nuances cambiantes de reconhecimento e ausência do sentido, 
da sensação e da palavra 'Professor', não são suficientes, pois se encontram ainda na arena estruturada e cansativa da interpretação que cega ao mundo, inventa micro-universos que se replicam, simulacros do decalque, do encontro do mesmo, naquilo que o gesto mínimo, ínfimo, na duração de uma bombinha explodindo no chão da sala de aula, faz esquecer...

Em contrapartida, se o hífen con'Ser'ta com uma pedagogia da 'palavra', da 'coisa' e do 'objeto', a pragmática estrutural - qual seja a palavra Professor confinada ao seu delineamento de forma - existe como signos, como objetos e coisas (continentes que criam um universo de onde eles devem estratificar e observar) e como conteúdo das coisas que é apenas delas, que não podem ser superpostas pela memória. As políticas da escrita aconteceriam à medida que as palavras ganhassem um caráter prático e que fossem colocadas a trabalhar ao mesmo tempo da ocorrência de nossas experiências. Assim, uma política cuja 'utopia' expressar-se-ia na falência ou na falácia da realidade experienciada poder 'Ser'-, Professor.

A política possível que é gerada no conflito com a experiência das coisas que ensinam e que não permitem réplicas, nem através do diálogo, nem a partir de qualquer ato educativo, auto-reflexivo ou que seja permeável a perpassar por entre 'Ser' es.

Uma escrita que ofereça a promessa de uma existência no discurso pedagógico e em suas características de inarticulação, fixidez e incontestabilidade. O hífen, inevitavelmente, neste contexto é autoritário. A tensão passa, portanto, entre conhecimentos, práticas e políticas (contexto, culturas, etc) e a experiência do objeto em si: há um registro escrito que afirme a possibilidade de resistência com e no vazio da hifenação? 


\section{$\mathrm{AC}$ e de.}

Um corpo pode o . (ponto) $\mathrm{O}$. pode deslocar-se pelo nome e apanhar as iniciais do composto (Afinal, você prefere que te chamem de Antonio ou de Carlos? Uai, não pode Antonio Carlos?) e para após o singular 'de', tão insensível a tudo mais que compõe o nome, por isso mesmo, torna-se um . incorpóreo. de.

Um corpo deseja-se . (ponto). O . encerra significados e completudes. Termina-se nome, e abre e fecha uma assinatura. $\mathrm{O}$. assina o testemunho memorial da vida, pessoal e acadêmica, uma trajetória temporal de 20 anos no magistério. $\mathrm{O}$. não vira reticências. .AC

Um corpo reflete-se contra . (ponto). O . adensa-se em mancha colorida, um carimbo espacial. Cartografias sensiveis que conectam os pontos de início e de fim. Um • que inicia um memorial que vira uma narrativa que se transforma em uma imaginação que se concentra em um corpo. e

Um . (ponto) no corpo. É pinta, é verruga, é casquinha de machucado, é bolinha de sangue. $\mathrm{O}$. aponta para a identidade nomeável e gargalha, baixinho e alto, ruidosamente. Ritmos de . a ponta do corpo, impressão digital das pontas do dedos, de fios . a . AC e de.

Um corpo pontilhado, a ser colorido, rabiscado e transpassado com giz de cera em mãos de criança. Um • que não cabe em $s i$, que não tem dimensão nem profundidade, é extensivo e, que contradição, fixo. Um • que é pingo de tinta em papel absorvente, que se espalha, sombreando a superfície. Um ., imagem de memorial, fragmento adensado. . (ponto)

Um • sem corpo, somente junções de letras e movimentos deambulatórios entre AC e de. ..... (pontos) nômades, vagabundos 
e ziguezagueantes. Em órbitas e em fractais e em parábolas e em vertigens. . capturado na intersecção entre duas retas. Pura singularidade cuja corporeidade quando o atinge é cedo ou tarde demais. . imemorial.

Hay que sacarlo todo afuera/ Como la primavera/ Nadie quiere que adentro algo se muera (História do Pranto. Alan Pauls)

O tic-tac, compasso da lembrança da infância, preenche agora o vazio sonoro da casa, adulta e amadurecida.

Do relógio da infância, extraem-se os movimentos que rangem em cordas pouco lubrificadas, e que estralam de vez em quando. $\mathrm{O}$ som que se apresenta em dificuldade de passar de um minuto ao outro. Sempre às tantas horas e vinte minutos. Às vezes, o tic-tac pára, por algum desnível acontecimental do eixo. Fica fora do eixo, e o pêndulo estagna, distrai-se nos vinte minutos e por ali fica observando a mudança da posição do sol, o balanço da cortina ao vento, e o zumbido dos marimbondos que se aproximam.

Com uma pequena chave, dá-se corda ao tempo. E com as pontas do dedo, o balanço do pêndulo é refeito. Tic-tac, tic-tac, tic-tac, tic-tac. O som figura os minutos em uma extensão tão enorme que são mais do que vinte anos de retorno. Passa o tempo nesta velocidade sobreposta de passado-futuro-presente. $\mathrm{O}$ tempo arquiva-se no baú sonoro que o relógio representa. Do baú sonoro pululam odores e lembranças com sabor de ..., de..., já não se sabe mais o sabor da lembrança.

Com o tic-tac-tac-tic-tac-tic-tic-tac-tic, os vacúolos do corpo que arrastava os sapatos, roçava-se em vestimentas que cobriam as 
pernas e braços, e esperava. Por uma crônica da vida diária, repetida, quase cansada e à qual o retorno dos anos é tão vivo quanto a materialidade do relógio. Madeira lixada e ornamentada, dobrada e decorada por flores vítreas, ranhuras leitosas na transparência. Memória guardada feito caixinha de música. De corda, manual e sem pressa.

(Reaproximação de um manuscrito perdido, conto que escrevi quando estava no segundo ano do ensino médio do Colégio Universitário da Universidade Federal de Viçosa, e que foi enviado a um concurso de contos pela minha professora de Português)

\section{Planos de sensação}

Sempre me intrigaram as magnólias, depois que soube que suas flores são de uma estrutura muito primitiva, ou talvez em outras palavras pouco evoluidas. A vida principal de acesso à Universidade Federal de Viçosa era uma coleção de árvores de magnólia, com seus exalados odores da noite, e sua cor pouco viva, pastel, sem atração vibrante durante o dia. Da minha graduação em Biologia, a atmosfera é assim: de cores pastéis, com cheiro de magnólia; de estrutura primitiva que persiste, que per-dura, que resiste; de cascas da árvore que, quando arrancadas, davam a ver pequenos artrópodos - um deles o pseudo-escorpião, tão pequenino, que me fascina até hoje; de qualquer motivo para me ausentar das salas de aula, e me envolver com atividades culturais, organização de congressos, movimento estudantil no centro acadêmico, reuniões de pesquisa, monitoria de ensino de ciências; 
de gosto de iogurte com abacaxi e sanduíche dos fins de tarde; de vento e brisa e céu azul que correm por uma bicicleta.

Toda essa atmosfera melancólica e nostálgica é o tempo de existência de uma personagem, uma forma de encontrei de deixá-la sobrevivendo, quieta, para nos tempos presentes poder passear por aqueles mesmos caminhos como se fosse estrangeiro, descansando como uma pêra se esquece dormindo em uma fruteira.

Essa personagem lembra-me, ocasionalmente, os sonhos que eu tinha e esqueci sobre a mesa: é nas andanças pelas retas da Universidade Federal de Viçosa que me/se encontro/encontra com os primeiros alunos das escolas públicas, com os compromissos políticos daquela época, com uma pulsão de retorno, por vezes incontrolável. Que se torna solta, leve, como um riso que eu tinha e esqueci entre os dentes.

Viver, violentamente, é esquecer e criar com a personagem um campo de multiplicidades paralelas. Uma passagem em que se/me encontra/encontro com um emaranhado de potencialidades do que poderia ter sido... E a personagem lembra-se/me de que o sol na sombra se esquece, dormindo numa cadeira...

As magnólias, estrangeiras num mundo 'mais evoluído', poluem o ar com um odor que pertenceu a outro tempo e que continua, persiste, per-dura.

Como me encanta pensar na memória do vivo, aquilo que se guardará na personagem do esquecimento, o que independe de nosso desejo de lembrar, e que nos aparece nas mais comuns das ações banais, repetidas e conhecidas.

Se puder nomear a personagem, gotejo-lhe as letras de professor. Se puder habitar a personagem, emolduro-lhe a palavra escola. Se puder esvaziar a personagem, deixo-lhe a superfície preconceito. 
Se puder arrancar a personagem do esquecimento, aprisiono-lhe no novelo história.

Pela invenção, resiste-se.

\section{Sob os olhos de alunos}

Lembranças em meio à névoa. Neblina da montanha, gotas de orvalhos molhando a grama ao amanhecer. Umidade elevada no ar. Lembranças em meio à névoa. Poeira vermelha, sol escaldante do início da tarde. Umidade rarefeita no ar. Névoa é a atordoada sensação de uma consciência por um fio, fio este que se estende e emaranha-se em tantos outros de recordações e acontecimentos por vir.

Nos meus últimos relatórios trienais de atividades docentes, na auto-avaliação venho pensando a respeito dos olhos dos alunos.

É no encontro com os estudantes de graduação que sempre experiencio o desassossego, o incômodo criativo e o enfrentamento - por vezes com muita sensação de violência - de ser professor em cursos de formação de professores para a educação básica nesta Universidade.

Estes encontros, marcados por nuances de um futuro dos estudantes que passa às vezes menos, às vezes mais, pelo interesse, desejo, vontade e compromisso 'com o mundo', de serem professoras e professores. É na graduação, que encontro o futuro, tempo tão ágil em escapar. Encontro este futuro pelos olhos de 


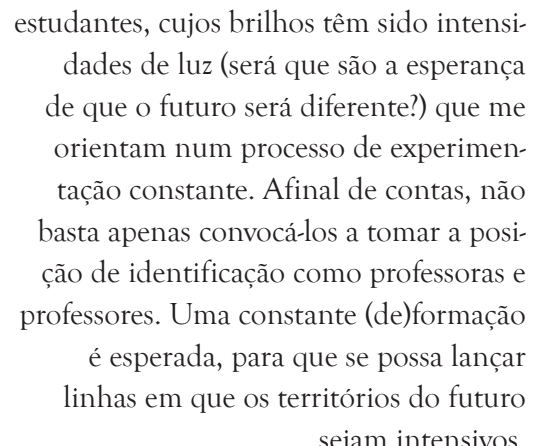

Do início da minha carreira como professor leigo de redação e português, e 'habilitado' de Ciências e Biologia, é sob os olhos dos alunos o flashback do símbolo do super-homem desenhado a giz no quadro da sexta-série A, dia após dia, durante meses. Eles acreditariam mesmo que eu fosse me transformar no superman? Das músicas sertanejas que dançávamos de pé no chão, e cantávamos para depois, com uma atitude de superação incrível, alguns alunos da quinta-série do Alto das Amoras em Viçosa/MG escreverem duas, três frases. Da escola estadual de bairro periférico de Campinas, na qual apenas a ingenuidade do mineiro do interior para acreditar que a violência degradante não era a perda da condição de humanidade dos alunos da oitava série B. Das minhas cinco aulas de Ciências, distribuídas em três dias da semana, para a classe de ensino supletivo de sétima série, e a escapada da escrita da dissertação de mestrado para adentrar na sala de aula, no universo daqueles estudantes adultos de cujo sorriso lembro-me até hoje. Das criações envolventes em aulas de laboratório, de estudos do meio, de leituras de textos sobre história e filosofia da ciência, de bate papos sobre temas menos comuns e mais cotidianos, da 
situação de dúvida que acompanhou muito de perto a aposta que os estudantes de ensino médio faziam do meu trabalho.

Como ainda persisto nesta ilusão que a escola plantou em mim?
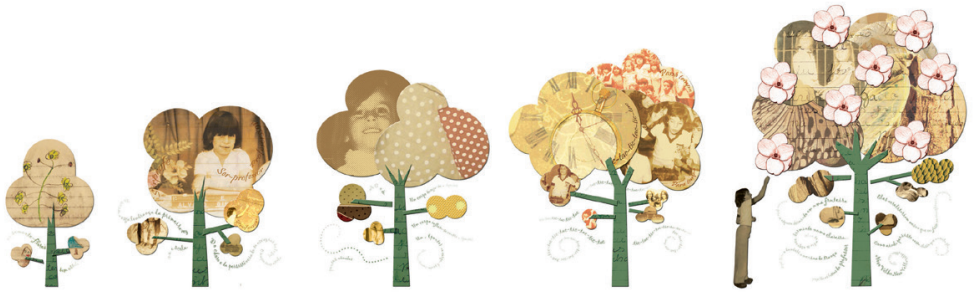